\title{
Consenso Brasileiro de Monitorização e Suporte Hemodinâmico - Parte V: Suporte Hemodinâmico
}

\author{
Brazilian Consensus of Monitoring and Hemodynamic \\ Support - Part V: Hemodynamic Support
}

\author{
Suzana Margareth Ajeje Lobo, Ederlon Rezende, Ciro Leite Mendes, \\ Álvaro Rea-Neto, Cid Marcos David, Fernando Suparregui Dias, Guilherme Schettino pelo \\ Painel de Especialistas do Consenso Brasileiro de Monitorização e Suporte Hemodinâmico.
}

\section{RESUMO}

JUSTIFICATIVA E OBJETIVOS: O choque ocorre quando o sistema circulatório não consegue manter a perfusão celular adequada. Caso ele não seja revertido a lesão celular irreversível instala-se. A terapia do choque tem como prioridade inicial à rápida recuperação da pressão arterial média e do debito cardíaco, e vigorosa para manter a vida e evitar ou diminuir as disfunções orgânicas. A reposição de fluídos, freqüentemente associada a fármacos vasoativas, é necessária para garantir adequada perfusão tecidual e a manutenção da função dos diferentes órgãos e sistemas, sempre guiados por monitorização cardiovascular. As recomendações listadas visam orientar o suporte hemodinâmico necessário para manter uma adequada perfusão celular.

MÉTODO: O processo de desenvolvimento de recomendações utilizou o método Delphi modificado para criar e quantificar o consenso entre os participantes. A AMIB determinou um coordenador para o Consenso, o qual escoIheu seis especialistas para comporem o Comitê Consultivo. Outros 18 peritos de diferentes regiões do país foram selecionados para completar o painel de 25 especialistas, médicos e enfermeiros. Um levantamento bibliográfico na MedLine de artigos na língua inglesa foi realizado no período de 1966 a 2004.

RESULTADOS: Foram apresentadas recomendações referentes a 17 questões sobre suporte hemodinâmico, com ênfase em reposição volêmica, transfusão de concentrados de hemácias, fármacos vasoativos e terapia de otimização hemodinâmica.

CONCLUSÕES: A monitorização hemodinâmica per se não é capaz de reduzir a mortalidade de pacientes graves. Os possíveis benefícios serão conseqüência da correta interpretação dos dados obtidos e do uso de protocolos de tratamento que permitam obtenção de metas hemodinâmicas adequadas.
Unitermos: Consenso, Monitorização Hemodinâmica, Recomendação, Suporte Hemodinâmico

\section{SUMMARY}

BACKGROUND AND OBJECTIVES: Shock occurs when the circulatory system cannot maintain adequate cellular perfusion. If this condition is not reverted irreversible cellular injury establishes. Shock treatment has as its initial priority the fast and vigorous correction of mean arterial pressure and cardiac output to maintain life and avoid or lessen organic dysfunctions. Fluid challenge and vasoactive drugs are necessary to warrant an adequate tissue perfusion and maintenance of function of different organs and systems, always guided by cardiovascular monitorization. The recommendations built in this consensus are aimed to guide hemodynamic support needed to maintain adequate tisular perfusion.

METHODS: Modified Delphi methodology was used to create and quantify the consensus between the participants. AMIB indicated a coordinator who invited more six experts in the area of monitoring and hemodynamic support to constitute the Consensus Advisory Board. Twenty five physician and two nurses selected from different regions of the country completed the expert panel, which reviewed the pertinent bibliography listed at the MEDLINE in the period from 1996 to 2004.

RESULTS: Recommendations were made answering 17 questions about hemodynamic support with focus on fluid challenge, red blood cell transfusions, vasoactive drugs and perioperative hemodynamic optimization.

CONCLUSIONS: Hemodynamic monitoring by itself does not reduce the mortality of critically ill patients, 
however, we believe that the correct interpretation of the data obtained by the hemodynamic monitoring and the use of hemodynamic support protocols based on well defined tissue perfusion goals can improve the outcome of these patients.

Key Words: Consensus, Hemodynamic Monitoring, Hemodynamic Support, Recommendation.

\section{INTRODUÇÃO}

O choque ocorre quando o sistema circulatório não consegue manter perfusão celular adequada. Apesar de diferentes etiologias, a progressão dessa síndrome é acompanhada de um padrão comum de sinais, sintomas e anormalidades laboratoriais. Caso o choque não seja revertido, a lesão celular irreversível instalase. A terapia do choque tem como prioridade inicial garantir a pressão arterial média e o débito cardíaco suficientes para manter o paciente vivo. A reposição de fluídos, freqüentemente associada a fármacos vasoativos, é necessária para garantir adequada perfusão tecidual e a manutenção da função dos diferentes órgãos e sistemas, sempre guiados por monitorização cardiovascular. As recomendações a seguir visam orientar o suporte hemodinâmico necessário para manter adequada perfusão celular e de diferentes órgãos e sistemas.

\section{QUESTÃO: DEVE-SE UTILIZAR CRISTALÓIDES OU COLÓIDES NA REPOSIÇÃO VOLÊMICA DO PA- CIENTE GRAVEMENTE ENFERMO?}

\section{Recomendações:}

1. A restauração da volemia deve ser obtida o mais precocemente possível e parece que o tempo influencia mais do que o tipo de solução cristalóide ou colóide administrado.

Grau B1

2. Considerando aspectos relativos ao seu baixo custo e poucos efeitos colaterais diretos, as soluções cristalóides são consideradas como primeira escolha na reposição volêmica inicial.

Grau D

3. Não existem benefícios claros com o uso de um colóide em relação ao outro.

Grau A2

4. Até o presente momento não existe recomendação para o uso sistemático de albumina na reposição volêmica.

Grau A1

\section{Racionais}

Cristalóide

As soluções cristalóides mais comumente utilizadas para reposição volêmica são as soluções fisiológicas a 0,9\% e de Ringer com lactato. Estas soluções atravessam facilmente a barreira endotelial e tendem a se acumular em maior quantidade no interstício, de tal forma que, ao final de uma hora, apenas $20 \%$ do volume infundido permanece no espaço intravascular, o que obriga uma reposição três a quatro vezes maior que a perda estimada ${ }^{1}$ Embora não existam estudos clínicos bem desenhados apontando para seu benefício inconteste, as taxas de morbidade e mortalidade parecem não diferir significativamente, quando se compara cristalóides com colóides durante o suporte hemodinâmico em pacientes gravemente enfermos ${ }^{2-4}$. Considerando seu baixo custo e efeitos colaterais menos expressivos, as soluções cristalóides podem ser utilizadas como primeira escolha para a maioria dos pacientes graves que necessitem reposição volêmica, como, por exemplo, na reanimação inicial da sepse grave/choque séptico, no trauma grave e no período peri-operatório.

A reposição volêmica agressiva com solução fisiológica a $0,9 \%$ é mais eficaz do que o Ringer com lactato, no entanto, pode levar à maior incidência de acidose metabólica hiperclorêmica e hipernatremia ${ }^{5,6}$. Podem ocorrer alterações da coagulação após grandes infusões de $\mathrm{NaCl}$. A acidose metabólica hiperclorêmica não está relacionada à infusão de Ringer com lactato. Quando grandes volumes de cristalóides são necessários, o uso do Ringer com lactato é preferencial.

Solução Hipertônica

As soluções hipertônicas expandem o volume intravascular, elevam a pressão arterial e o débito cardíaco com pequenos volumes e favorecem o fluxo de água do interstício para o intravascular, principalmente através de rápida mobilização de líquido intracelular para o intravascular, podendo expandir a volemia em até 10 vezes mais do que a solução de Ringer com lactato ${ }^{7,8}$. Considerando seus efeitos de rápida expansão volêmica com baixo volume e melhora da função cardiovascular (aumento da pré-carga e redução da pós-carga), seu uso tem sido sugerido para reposição inicial no choque hemorrágico, principalmente em situações de atendimento pré-hospitalar com sangramento controlado e em politraumatizados com trauma cranioencefálico, por reduzir a pressão intracraniana e melhorar o fluxo sangüíneo encefálico ${ }^{8-14}$. Efeitos imunomoduladores e benefícios na reanima- 
ção de queimados também têm sido sugeridos ${ }^{8,9}$. Em pacientes com sepse grave, ela determina melhora no desempenho cardiovascular, avaliada pela POAP e pelo $\mathrm{DC}^{15}$. Contudo, seus efeitos são temporários e apresentam riscos de efeitos colaterais como hipernatremia, hipercloremia e hiperosmolaridade que podem provocar mielinólise pontina e convulsões, o que limita o seu uso ${ }^{7}$. Os efeitos benéficos observados com o uso da solução hipertônica são temporários. Outras soluções com maior permanência intravascular têm sido adicionadas à solução hipertônica com o objetivo de prolongar sua eficácia ${ }^{11-14}$. Apesar dos possíveis benefícios sugeridos para algumas situações, ainda não há definição clara de recomendações para o seu uso ${ }^{10,11}$.

\section{Amido}

Devido à sua característica de produzir expansão plasmática rápida e duradoura, pode ser considerado como alternativa à reposição volêmica em pacientes graves, sobretudo naqueles com permeabilidade capilar alterada nos quais se deseja restabelecer mais rapidamente o volume circulante ou que apresentam baixa resposta inicial ao uso do cristalóide ${ }^{2,4,16}$. Os amidos são caracterizados pelas suas diferentes concentrações $(3 \%, 6 \%$ e $10 \%)$, diferentes pesos moleculares $(70.000,130.000,200.000$ e 450.000$)$ e diferentes graus de substituição $(0,4,0,5,0,62$ e 0,7$)$. Estas diferenças são particularmente importantes para se determinar os efeitos de expansão plasmática e pressão oncótica, meia-vida no espaço intravascular e efeitos sobre o sistema de coagulação e anafilaxia ${ }^{16-22}$.

A maior evidência na literatura com o uso de amido é oriunda de estudos envolvendo pacientes instáveis do ponto de vista hemodinâmico e no período pósoperatório de cirurgias de grande porte (200/0,5 - 20 a $35 \mathrm{~mL} / \mathrm{kg} /$ dia e 130/0,4 - $50 \mathrm{~mL} / \mathrm{kg} / \mathrm{dia})$. O uso de amido como expansor plasmático foi associado como fator de risco independente para insuficiência renal em pacientes sépticos ${ }^{21}$. Lesões histológicas do tipo "osmose induzidas" foram observadas nos rins após transplante renal, quando amidos foram usados no doador ${ }^{23}$. A deposição dos amidos em diversos tecidos tem sido associada com prurido e, reação anafilática pode ocorrer raramente. Distúrbios na coagulação são caracterizados por alteração na função plaquetária e na formação do coágulo por interferência no fator VIII e complexo de Von Willebrand ${ }^{18,19}$. Caso se opte pelo uso dos amidos, devem-se adotar precauções como a monitorização diária da função renal e da coagulação, observar a dose máxima recomendada, não os utili- zando por mais do que 5 dias consecutivos e evitar seu uso em pacientes com risco de sangramento.

Embora não existam grandes estudos comparando os diferentes tipos de HES às novas soluções (200/0,5 e $130 / 0,4)$, estas parecem ser mais seguras, sobretudo em relação à função renal e alterações sobre a coagulação. Embora os novos amidos apresentem propriedades farmacológicas favoráveis, ainda não existem evidências de que uma solução colóide seja superior à outra ${ }^{22}$.

Gelatina

As gelatinas são oriundas de colágeno hidrolizado de bovinos, disponíveis em soluções a $3,5 \%$ e a $5,5 \%$ em diferentes preparações e com diferentes concentrações eletrolíticas. Podem ser consideradas como alternativa, quando se deseja uma expansão mais rápida. Como todo colóide, apresenta maior custo que os cristalóides.

Em comparação com outros colóides, de maneira geral, apresentam menos efeitos colaterais, principalmente em relação às alterações da coagulação e da função renal, são de baixo custo e não têm limitação de doses. Entretanto, promovem menor expansão plasmática e têm permanência mais curta no espaço intravascular. A incidência de reação anafilática é maior devido à liberação de histamina ${ }^{2,4,17,22,24}$.

Cabe ressaltar que a gelatina fluida modificada apresenta uma molécula mais estável e com maior duração do efeito de expansão plasmática sendo, portanto, mais adequada para reposição nos pacientes graves.

\section{Dextran}

Os dextrans são polímeros de glicose produzidos a partir de bactérias cultivadas em meio de sacarose. São descritos pelos seus pesos moleculares como Dextran $40(40.000 \mathrm{Da})$ e Dextran $70(70.000 \mathrm{Da})$ e estão disponíveis associados à soluções fisiológicas hipertônicas, isotônicas e de glicose ${ }^{17}$. O benefício teórico do uso do Dextran, assim como outros ccolóides, seria na necessidade de urgência da expansão plasmática ou quando se desejasse aumentar a pressão oncótica. Entretanto, o uso de Dextran está diminuindo gradativamente em todo mundo, principalmente devido aos seus efeitos colaterais e menor tempo de permanência no espaço intravascular, em comparação com outros colóides ${ }^{2,4,17,25}$.

Devido ao risco de reações anafiláticas, disfunção da coagulação, insuficiência renal aguda, volume possível limitado de infusão, bem como a falta de estudos 
demonstrando efeitos benéficos em comparação à reanimação volêmica com soluções cristalóides, não se justifica sua recomendação, principalmente quando outros colóides estão disponíveis.

\section{Albumina}

Durante o suporte hemodinâmico, o uso de albumina em pacientes com hipoalbuminemia, hipovolemia ou grandes queimaduras não pode ser recomendado com base em seus níveis séricos ${ }^{26}$. Um estudo aleatório utilizando albumina em solução a 5\% e comparando-a ao cristalóide, mostrou não haver benefício de uma solução em relação à outra, no que se refere à mortalida$\mathrm{de}^{27}$. Seu uso pode ser considerado em pacientes que necessitem de reposição de colóides para aumentar a pressão oncótica e por motivos de intolerância a colóides sintéticos. Seu alto custo deve ser considerado.

A co-administração de albumina melhora a resposta diurética obtida com furosemida em pacientes cirróticos com ascite ${ }^{28}$. Contudo, em pacientes com cirrose e peritonite bacteriana espontânea, o uso de albumina diminuiu significativamente a morbidade e a mortalida$\mathrm{de}^{29}$. O emprego de albumina também é justificado nas paracenteses volumosas e no manuseio de plasmaférese $^{30}$.

Alguns estudos têm sugerido segurança e efeito benéfico no uso de albumina (efeito antioxidante e hemodinâmico) acompanhada de diuréticos em casos de lesão pulmonar aguda e menor mortalidade em pacientes com o uso de albumina no pós-operatório de cirurgia cardíaca ${ }^{31-34}$.

\section{QUESTÃO: QUANDO E COMO USAR CONCENTRA- DO DE HEMÁCIAS?}

Recomendações:

1. O concentrado de hemácias deve ser utilizado como parte do algoritmo de reanimação inicial da sepse grave e do choque séptico, quando não foram atingidas as metas terapêuticas após a reposição volêmica e a infusão de dobutamina. O valor alvo é um nível de hemoglobina maior ou igual a $10 \mathrm{~g} \%$.

Grau B1.

2. Quando a hemoglobina for menor que $10 \mathrm{~g} \%$, ou na presença de sinais de deficiência na oxigenação que não responderam a outras medidas em cardiopatas, coronarianos e naqueles com hemorragia aguda. Os valores alvo são $\mathrm{Hb} \geq 10 \mathrm{~g} \%$ ou até que sejam revertidos os sinais de deficiência na oxigenação.

Grau B3
3. Quando inferior a $7 \mathrm{~g} \%$, na presença de sinais de deficiência de oxigenação não responsiva a outras medidas em qualquer grupo de pacientes. Os valores alvo de $\mathrm{Hb}$ variam entre 7 e $9 \mathrm{~g} \%$.

Grau B3

4. Nos sangramentos agudos volumosos, a medida instantânea da hemoglobina não reflete as perdas. Nestes casos, recomenda-se a reposição guiada pela observação clínica. Nos pacientes politraumatizados que apresentem grande predisposição a sangramentos volumosos, é indicada para manter os níveis de $\mathrm{Hb}$ num patamar acima do limite considerado critico para sua condição clínica.

Grau C

5. As medidas ou protocolos para reduzir a perda sangüínea e aumento da hematopoiese devem ser incentivados.

Grau D

6. Recomenda-se que o concentrado de glóbulos seja "lavado" e com pouca concentração de leucócitos.

Grau D

Racional: A oferta global de oxigênio é determinada apenas pelo débito cardíaco e pelo conteúdo sangüíneo de oxigênio. O principal determinante deste último é a saturação da hemoglobina. A hemoglobina é a única forma natural de transportar oxigênio em quantidades significativas. Desta forma, existe base racional para administração de concentrado de hemácias como forma de melhorar a oxigenação tecidual. Apesar dos argumentos, a administração de concentrado de hemácias não produz melhora no consumo de oxigênio em pacientes gravemente enfermos, fora do período de reanimação inicial do choque ${ }^{35}$. Essa incapacidade em aumentar o consumo de oxigênio é observada mesmo quando são empregadas hemácias frescas, com pouco tempo de estocagem ${ }^{36}$. Nas primeiras seis horas do atendimento da sepse grave ou choque séptico, a manutenção da $\mathrm{Hb} \geq 10 \mathrm{~g} \%$ dentro de um algoritmo de reposição volêmica e infusão de dobutamina guiado pela $\mathrm{ScvO}_{2}$, demonstrou melhora na sobrevida ${ }^{37}$.

A anemia é muito comum nas UTI, como decorrência de perdas, diluição e redução na hematopoie$\mathrm{se}^{38}$. Concentrações de hemoglobina abaixo de 10 $\mathrm{g} \%$ são bem toleradas na maioria dos cenários clíni$\cos ^{39}$. Em pacientes com infarto agudo do miocárdio, angina instável, acidente vascular encefálico isquêmico, hemorragia aguda e SDRA existem evidências de benefício em manter níveis mais elevados de hemoglobina ${ }^{40-42}$.

Existe risco significativo de transmissão de agentes 
infecciosos, de propiciar infecções nosocomiais e de piora no perfil imunológico ${ }^{43,44}$. A maior parte dos efeitos danosos das transfusões é produzida através da transferência de leucócitos e plaquetas ${ }^{45}$. A administração de concentrado de hemácias é fator independente para discriminar morbidade e mortalidade em pacientes internados nas UTI47. As medidas para poupar a perda de sangue e aumentar a hematopoiese são eficazes na prevenção de transfusões ${ }^{46}$.

\section{QUESTÃO: QUANDO E COMO USAR DOPEXAMI- NA?}

Recomendações:

1. Quando existe refratariedade ao uso prolongado de dobutamina ou dopamina, atribuída a dessensibilização de receptores adrenérgicos.

Grau D

2. Quando se objetiva privilegiar os fluxos sangüíneos renal, hepático ou esplâncnico nos pacientes em que a vasodilatação não seja proibitiva.

Grau B3

Racional: A dopexamina é uma catecolamina sintética, derivada da dopamina, com efeito inotrópico e vasodilatador. Sua ação é intermediada por uma pequena atuação sobre receptores $\beta_{1}$ adrenérgicos e dopaminérgicos dos tipos 1 e 2 , associada à grande manifestação sobre receptores $\beta_{2}$ O seu efeito predominante é a vasodilatação e a taquicardia. $\mathrm{O}$ aumento do débito cardíaco observado é secundário à taquicardia e a diminuição na resistência vascular sistêmica, somados a um inotropismo discreto. A ação sobre receptores $\beta_{2}$ promove ação calorigênica e antiinflamatória, sobretudo quando empregada em altas doses e por tempo prolongado ${ }^{47}$. A dopexamina já foi estudada no choque séptico, em pacientes gravemente enfermos, no pósoperatório de cirurgias cardíacas e durante cirurgias abdominais de grande porte ${ }^{48-53}$. Em diversos grupos de pacientes, a dopexamina produziu aumento do fluxo sangüíneo esplâncnico, hepático e renal, superior à elevação no débito cardíaco.

\section{QUESTÃO: QUANDO E COMO USAR FENILEFRINA?}

Recomendações:

1. Assim como a noradrenalina, pode ser utilizada para elevação da pressão arterial em pacientes neurológicos nos quais se pretende melhorar a pressão de perfusão encefálica.

Grau B3
2. Como segunda escolha na elevação da pressão arterial em pacientes sépticos refratários a outras catecolaminas ou na hipotensão associada à vasodilatação de outras origens. Esta indicação é mais consistente quando se quer evitar taquicardia e quando não se objetiva um efeito inotrópico positivo.

Grau D

Racional: A fenilefrina é uma catecolamina sintética que possui ação intensa e exclusiva sobre receptores $\alpha_{1}$ adrenérgicos. O seu efeito mais observado é a vasoconstrição generalizada sem indução concomitante de taquicardia. Por não ter efeito seletivo, pode induzir vasoconstrições pulmonar e esplâncnica que são potencialmente prejudiciais em vários pacientes. Pode ocorrer redução no débito cardíaco secundário à elevação da resistência vascular sistêmica, sobretudo em cardiopatas. A sua depuração rápida Ihe confere uma ação muito fugaz, obrigando a uma grande vigilância na infusão contínua. A ação $\alpha_{1}$ prolongada pode produzir uma mudança no perfil metabólico, que propicia o aparecimento de inflamação.

O uso mais freqüente e conhecido da fenilefrina é nos pacientes neurológicos, quando o objetivo é melhorar a pressão de perfusão encefálica através do aumento da pressão arterial sistêmica ${ }^{54,55}$. Nesta indicação, a fenilefrina é consagrada e comparável à noradrenalina. Além dos pacientes neurológicos, a fenilefrina foi verificada basicamente em pacientes sépticos e quadros de vasodilatação intensa ou refratária, como observada em choque anafilático, no uso de circulação extracorpórea e na hipotensão induzida por anestesia ${ }^{56-59}$. Em todos estes cenários exerceu um significativo efeito vasoconstritor capaz de reverter a hipotensão arterial ou choque.

\section{QUESTÃO: QUANDO E COMO USAR A VASOPRES- SINA?}

Recomendações:

1. Como fármaco de primeira linha na parada cardíaca, de acordo com o algoritmo do ACLS.

Grau B1

2. No choque séptico, quando houver hipotensão arterial secundária ao choque refratário aos agentes adrenérgicos.

Grau D

3. Na manutenção do potencial doador com morte encefálica.

Grau B3

Racional: A vasopressina é um hormônio com efeitos 
importantes no equilíbrio osmótico e vasomotor. A sua ação vasoconstritora é mediada por receptores de vasopressina do tipo 1 , pela modulação de canais de $\mathrm{K}_{\text {ATP }}$, modulação do óxido nítrico e por potencialização da ação de agentes adrenérgicos.

O uso mais comum e documentado da vasopressina é na parada cardíaca. O algoritmo atual do ACLS preconiza a utilização de dose única, em bolus, de vasopressina no atendimento inicial da fibrilação ventricular. No entanto, existem dados que evidenciam um grande poder da vasopressina na reanimação, comparável ou mesmo superior ao da adrenalina, nos casos de assistolia, fibrilação ventricular e atividade elétrica sem pulso ${ }^{60,61}$. O nível sérico de vasopressina encontra-se baixo em algumas doenças com vasodilatação persistente, como o choque séptico e naquele do potencial doador com morte encefálica ${ }^{62,63}$. Nestas condições, a infusão por via venosa adicional de vasopressina corrige inclusive a hipotensão ou vasodilatação refratária ao uso isolado de catecolaminas ${ }^{64}$.

A resposta vasoconstritora à vasopressina é muito variável órgão a órgão e mostra-se também muito heterogênea, de acordo com características genéticas dos pacientes. Em diversos grupos de pacientes, ficou evidenciada a redução do fluxo sangüíneo esplâncnico com o seu emprego ${ }^{65}$. A margem de dose terapêutica da vasopressina é bastante estreita, surgindo vasoconstrição deletéria com doses ligeiramente superiores à dose mínima preconizada de 0,04 a $0,10 \mathrm{U} / \mathrm{min}$.

\section{QUESTÃO: QUANDO E COMO USAR ADRENALINA?}

\section{Recomendações:}

1. Devido ao seu potencial em causar vasoconstrição grave, isquemia esplâncnica, aumento do consumo de oxigênio pelo miocárdio e disritmias cardíacas, a adrenalina deve ser usada com cautela e tem indicações bastante restritas na terapêutica do choque.

Grau B3

Racional: A adrenalina tem predominantemente efeitos alfa-adrenérgicos levando à importante vasoconstrição e aumento na pressão arterial|6-68. Pode ser usada em pacientes com choque refratário e que não respondem a outros vasopressores. No choque séptico refratário que não responde ao uso de dopamina, a adrenalina restaura, de forma adequada e comparável à associação de noradrenalina com dose fixa de dobutamina (5 $\mathrm{mg} / \mathrm{kg} / \mathrm{mim}$ ), os parâmetros hemodinâmicos globais, mas leva a importante aumento no consumo de oxigênio no trato gastrintestinal e nos níveis séricos de lactato ${ }^{68,69}$.

A adrenalina aparece como primeira opção na reanimação cardiopulmonar pós-parada cardíaca e no choque anafilático. Também pode ser usada no broncoespasmo grave e em caso de choque refratário.

A dose inicial preconizada é de 0,05 a 0,1 $\mathrm{\mu g} / \mathrm{kg} / \mathrm{min}$, podendo ser aumentada a cada 10 minutos e não ultrapassando $2 \mu \mathrm{g} / \mathrm{kg} / \mathrm{min}$. Na RCP, a dose é $1 \mathrm{mg}$ em bolus, por via venosa, ou diluído em $20 \mathrm{~mL}$ de água destilada ou solução fisiológica via tubo traqueal cada 3 a 5 minutos, de acordo com a resposta.

\section{QUESTÃO: QUANDO E COMO USAR DOBUTAMINA?}

Recomendações:

1. É o agente inotrópico de escolha no paciente gravemente enfermo.

Grau B3

2. É o agente de primeira linha nos pacientes com choque séptico.

Grau B1

Racional: Seu uso é indicado especialmente quando a disfunção do miocárdio é um componente importante do quadro clinico ${ }^{70}$. No choque cardiogênico ou na insuficiência cardíaca congestiva grave, a dobutamina eleva de forma consistente o débito cardíaco. No choque séptico, o uso de dobutamina, dirigido pela $\mathrm{SvO}_{2}$, deve ser precoce, isto é, nas primeiras seis horas de atendimento, visando à melhora da perfusão tecidu$\mathrm{a}^{37}$. Na fase mais tardia da sepse, a dobutamina deve ser indicada na presença de sinais de hipoperfusão ou quando houver resposta positiva à sua infusão, com aumento do consumo de oxigênio ${ }^{69,71}$.

A dobutamina, por seus efeitos beta-adrenérgicos, pode desencadear hipotensão. Nesses casos, um teste de volume deve ser realizado, pois a ocorrência de hipovolemia é muito provável. Por seus efeitos benéficos favorecendo a circulação esplâncnica, seu uso deve ser considerado em associação à noradrenalina durante o choque séptico ${ }^{72,73}$. A dobutamina pode causar disritmias cardíacas. As doses preconizadas variam de 2 a $20 \mu \mathrm{g} / \mathrm{kg} / \mathrm{min}$.

\section{QUESTÃO: QUANDO E COMO USAR DOPAMINA?}

Recomendações:

1. Como vasopressor na presença de bradicardia ou quando se deseja um efeito inotrópico associado, pode 
ser o fármaco de primeira escolha.

Grau D

Racional: A dopamina apresenta efeito inotrópico, vasopressor, vasodilatador renal e diurético ${ }^{74-77}$. Poderia ser utilizada em pacientes com evidências de disfunção miocárdica e vasodilatação com hipotensão de grau moderado. Entretanto, deve-se considerar que os diuréticos de alça são mais potentes e seguros quando se deseja um efeito diurético, dobutamina seria uma opção mais segura para os pacientes com necessidade de inotrópicos e noradrenalina seria melhor opção como vasopressor. Ainda, devem-se considerar dois fatos: primeiro, o efeito taquicárdico da dopamina; e segundo, que a indução de diurese não é interessante para a perfusão tecidual na sepse. Baixas doses de dopamina aumentam o fluxo esplâncnico, mas podem desviar o fluxo da mucosa do trato gastrintestinal ${ }^{78}$. Há indícios de pior resposta à dopamina do que à noradrenalina em pacientes gravemente vasoplégicos ${ }^{79}$. A dose varia de 3 a $20 \mu \mathrm{g} / \mathrm{kg} / \mathrm{min}$.

\section{QUESTÃO: DOPAMINA EM DOSE "DOPAMINÉRGI- CA" PARA "PROTEÇÃO RENAL" DEVE SER UTILI-} ZADA?

Recomendação: Não

Grau A2

Racional: Nenhum estudo clínico evidenciou efeito de proteção renal com o uso de dopamina em doses "dopaminérgicas". Apesar de seu efeito natriurético, o uso de dopamina, em recente metánalise, não evidenciou redução na incidência de insuficiência renal aguda, necessidade de diálise ou redução de mortalidade. Apresenta ainda inúmeros outros efeitos indesejáveis, como aumento da atividade da renina plasmática, taquicardia, disritmia cardíaca, isquemia miocárdica, infarto agudo do miocárdio, depressão do centro respiratório, necrose digital, isquemia do trato gastrintestinal e efeitos endócrinos e imunológicos indesejáveis ${ }^{80,81}$.

\section{QUESTÃO: QUANDO E COMO USAR NORADRENA- LINA?}

Recomendação:

1. É o fármaco de primeira escolha para pacientes hipotensos que não responderam à infusão de líquidos, especialmente quando a etiologia da hipotensão é o choque séptico.

Grau B2

Racional: A noradrenalina estimula os receptores alfa e beta-adrenérgicos, com efeito beta menos pronunciados. É mais efetiva em aumentar a PAM do que a dopamina em pacientes com choque séptico ${ }^{80}$. Deve-se evitar no choque hemorrágico ou hipovolêmico, pelo risco de lesão renal. Evidências estão se acumulando no sentido de indicar que a noradrenalina pode meIhorar a perfusão renal e esplâncnica em pacientes em choque séptico $0^{68,69,78,79,82-87}$. Também pode ser utilizada em outros tipos de choque, nos quais as pressões de perfusão coronariana ou encefálica estejam ameaçadas. Utiliza-se inicialmente em doses de 0,05 a 0,1 $\mu \mathrm{g} /$ $\mathrm{kg} / \mathrm{min}$, que podem ser aumentadas progressivamente, de acordo com o efeito hemodinâmico desejado e com o surgimento de efeitos colaterais importantes.

\section{QUESTÃO: QUANDO E COMO USAR INIBIDORES DA FOSFODIESTERASE?}

Recomendações:

1. Como terapêutica inotrópica adjuvante nos casos de insuficiência cardíaca congestiva (ICC) onde o uso isolado da dobutamina não é satisfatório, devendo ser usados por curto período.

Grau D

2. Não estão indicados no choque séptico.

Grau D

Racional: Os inibidores da fosfodiesterase são agentes vasodilatadores indicados no choque cardiogênico para aumentar a contratilidade miocárdica, porém, podem agravar a hipotensão se houver componente vasoplégico ${ }^{88-92}$. Eles melhoram a propriedade de lusitropia do músculo cardíaco, ou seja, sua capacidade de relaxamento. ${ }^{88-93}$ Estes medicamentos não dependem da integridade dos receptores beta-adrenérgicos. Parecem ser mais eficazes em pacientes com ICC de origem não-isquêmica. No entanto, um grande estudo clínico, aleatório, em pacientes com ICC descompensada não mostrou, em longo prazo, melhora na sobrevida. Do ponto de vista hemodinâmico, a milrinona restaura o débito cardíaco e reduz pressões de enchimento ${ }^{88}$. Há um estudo que sugere efeito antiinflamatório, propondo que seu uso poderia ser interessante no pós-operatório de cirurgia cardíaca ${ }^{93}$. A dose é $0,75 \mu \mathrm{g} / \mathrm{kg}$ em bolus, seguido de infusão contínua de $0,5 \mu \mathrm{g} / \mathrm{kg} / \mathrm{min}$.

\section{QUESTÃO: QUANDO E COMO USAR LEVOSI- MENDAN?}

Recomendação:

1. Em pacientes com insuficiência cardíaca congestiva 
(ICC) crônica agudizada e grave disfunção ventricular esquerda.

Grau B1

Racional: O levosimendan é um agente sensibilizador do cálcio utilizado para tratamento de ICC. Tem efeito inotrópico positivo baseado na ligação do fármaco à troponina cardíaca $\mathrm{C}$ mediada pelo cálcio ${ }^{94}$. Atua também abrindo os canais de potássio dependentes de ATP na musculatura lisa dos vasos, induzindo assim vasodilatação e reduzindo as pressões de enchimento. Aumenta o volume sistólico, a freqüência cardíaca e reduz a pressão de oclusão da artéria pulmonar. Ao contrário do emprego de dobutamina, tem sido demonstrada eficácia na redução de mortalidade em longo prazo $^{94}$. Pequenos estudos e casos clínicos sugerem benefícios em pacientes com falência aguda, pós-operatório de cirurgias (inclusive cardíaca), disfunção aguda de VD, miocardiopatia periparto e sepse. Alguns estudos mostraram benefício e segurança do fármaco também em infusões contínuas por sete dias em pacientes com ICC grave ${ }^{94}$. Resultados preliminares mostraram benefício de sobrevida em pacientes com insuficiência cardíaca de baixo débito e insuficiência cardíaca de instalação recente após infarto agudo do miocárdio. Apresenta a vantagem de aumentar o inotropismo, causando efeitos mínimos na demanda energética do miocárdio, além de ser menos disritmogênico. Estudo importante demonstrou menor mortalidade com o seu uso, quando comparado ao uso da dobutamina, em pacientes com insuficiência cardíaca grave de baixo débito ${ }^{95}$. Há um pequeno estudo mostrando que o levosimendan pode ser usado e com sucesso em pacientes com choque cardiogênico. Não deve ser administrada em pacientes com insuficiência hepática ou renal.

\section{QUESTÃO: QUANDO E COMO USAR CORTICÓIDES EM BAIXAS DOSES?}

Recomendações:

1. Na hipotensão arterial associada à insuficiência adrenal documentada.

Grau B1

2. No choque séptico com hipotensão arterial só controlada com altas doses de catecolaminas.

Grau B1

Racional: O cortisol é um hormônio com importante função sobre o metabolismo e a hemodinâmica. Um fator de grande relevância é a sua modulação na resposta às catecolaminas e outras substâncias com ati- vidade vasomotora. A deficiência absoluta ou relativa de cortisol resulta em hipotensão arterial e choque. Outro efeito significativo do cortisol é sua ação antiinflamatória através da produção de heat shock proteins, menor produção de citocinas, redução na cascata do ácido araquidônico, menor atividade da ciclooxigenase-2 e redução da forma induzível do óxido nítrico sintetase. Na presença de hipotensão arterial, já foi comprovada a existência de níveis baixos de cortisol ou resposta insuficiente ao teste de estímulo com ACTH em algumas doenças: choque séptico, AIDS, meningite bacteriana e hipotiroidismo ${ }^{96}$. Este resultado correlaciona-se com maior mortalidade, independentemente da etiologia.

A administração de corticosteróides em doses elevadas mostrou efeito deletério sobre a mortalidade de pacientes em choque séptico ${ }^{97-99}$. Por outro lado, a reposição em doses fisiológicas ou doses de estresse produz impacto positivo na taxa de reversão do choque e na mortalidade de pacientes hipotensos com insuficiência adrenal documentada ou naqueles com hipotensão que demandam doses elevadas de catecolaminas ${ }^{100-102}$. A dose recomendada de hidrocortisona é de 200 a $300 \mathrm{mg} /$ dia, divididas em três doses, durante sete dias. A retirada deve ser feita de forma gradual após sete dias ou diante da possibilidade de se reduzir mais precocemente o uso dos fármacos vasoativos ${ }^{103}$.

\section{QUESTÃO: A META DE OTIMIZAÇÃO HEMODINÂ- MICA COM VALORES SUPRANORMAIS EM PA- CIENTES CIRÚRGICOS DE ALTO RISCO E SEM DISFUNÇÃO ORGÂNICA ESTABELECIDA ESTÁ IN- DICADA?}

Recomendação: Sim.

Racional: A utilização da estratégia de otimização peri-operatória deve ser indicada precocemente, em pacientes de alto risco e baseada em um protocolo terapêutico que consiga promover melhora da oferta de oxigênio.

Grau A2

Racional: A observação dos padrões hemodinâmicos em falências circulatórias agudas demonstrou que, após diminuição inicial nas variáveis de fluxo sanguíneo e no consumo de oxigênio $\left(\mathrm{VO}_{2}\right)$, ocorre recuperação das variáveis com aumento desses índices e que os sobreviventes têm maior capacidade de recuperação do que não sobreviventes. Estes dados são consistentes com a hipótese de que as alterações no 
transporte de oxigênio que estiveram relacionadas com melhor evolução e sobrevida representam os efeitos de lesão associadas a compensações fisiológicas adequadas, o que leva à melhora da perfusão e da oxigenação tecidual. Desta maneira, esses índices de transporte de oxigênio, obtidos com o uso do cateter de artéria pulmonar (CAP), deveriam ser usados como metas terapêuticas, em pacientes com risco de evolução complicada ${ }^{104}$.

Shoemaker e col. demonstraram que a terapêutica de otimização peri-operatória (TOP) com a dobutamina, dirigida para metas supranormais em pacientes com alto risco cirúrgico, levou à redução significativa da morbimortalidade ${ }^{104}$. Outros estudos demonstraram resultados semelhantes com metas terapêuticas supranormais, com o uso de dobutamina ou de dopexamina $^{105-110}$.

Estes resultados bastante favoráveis, no entanto, não foram demonstrados em alguns estudos realizados em pacientes cujas metas foram dirigidas para valores normais ${ }^{110-113}$. A TOP dirigida para valores supranormais de IC realizada tardiamente, isto é, após a admissão do pacientes cirúrgicos gravemente enfermos na UTI, não demonstrou melhora na sobrevida ${ }^{114}$. Da mesma forma, a TOP com dopexamina falhou em demonstrar benefícios em pacientes de baixo risco cirúrgico ${ }^{53,113,114}$.

Os resultados de metanálises, por sua vez, têm sido, em sua maioria, favoráveis a TOP de pacientes cirúrgicos. Ivanov e col. avaliaram 16 estudos controlados e aleatórios, realizados em diferentes populações de pacientes graves e concluiram que havia uma tendência à diminuição de $19 \%$ no risco de morte, com efeitos favoráveis, na sua maioria, em grupos de pacientes cirúrgicos ${ }^{115}$. Heyland e col. relataram que a otimização das variáveis de transporte de oxigênio para metas supranormais não alterou a mortalidade em grupos heterogêneos de pacientes gravemente enfermos, mas sugeriram benefícios em grupos de pacientes cirúrgicos nos quais a otimização era iniciada no pré-operatório ${ }^{116}$.

Numa recente metanálise, foram avaliados os resultados de 21 estudos clínicos aleatórios ${ }^{117}$. Avaliando-se a mortalidade em pacientes de alto risco (mortalidade do grupo controle $>20 \%$ ), sete estudos demonstraram redução de $23 \%$ na mortalidade com a otimização precoce. Em seis estudos, nos quais a otimização foi realizada após o desenvolvimento de disfunções orgânicas, não foi demonstrada diminuição na mortalidade. A evolução também não melhorou significativamente nos grupos de pacientes menos graves (grupos com mortalidade no grupo controle $<15 \%$ ) e em pacientes cuja abordagem teve como metas terapêuticas níveis normais de $\mathrm{DO}_{2}$.

A abordagem de otimização, quando realizada tardiamente, não é efetiva, uma vez que falências orgânicas e lesão celular irreversível já estão presentes. Não são observados benefícios com a TOP quando não há diferenças significativas nas terapêuticas oferecidas para os grupos controle e protocolo, assim como em populações de pacientes de menor risco de morte. Todavia, estes dados em conjunto demonstram que a intervenção precoce, isto é, antes do aparecimento de disfunções orgânicas, com a TOP dirigida pelo CAP para metas terapêuticas ótimas (índices supranormais de IC e $\mathrm{DO}_{2}$ ) levam a redução significativa na mortalidade e na prevalência de falências orgânicas em pacientes cirúrgicos de alto risco.

\section{QUESTÃO: A META DE OTIMIZAÇÃO HEMODINÂMI- CA COM VALORES SUPRANORMAIS EM PACIEN- TES COM CHOQUE SÉPTICO ESTÁ INDICADA?}

Recomendação: Não, a utilização de valores supranormais de $\mathrm{IC}$ e $\mathrm{DO}_{2}$ dirigidos pelo CAP na fase não precoce do choque séptico (após admissão na UTI), não mostrou redução na morbidade e mortalidade. As variáveis cardiorrespiratórias obtidas com o CAP devem ser dirigidas de forma individualizada.

Grau A1

Racional: No choque séptico, as alterações fisiológicas complexas compreendem a presença de hipovolemia relativa e absoluta, vasodilatação, disfunção miocárdica e alterações do metabolismo e função celular resultando em hipóxia tecidual e demanda aumentada de $\mathrm{O}_{2}$. Estudos experimentais com sepse, a presença de maior $\mathrm{DO}_{2}$ espontânea associa-se a meIhor sobrevida em animais com choque endotóxico ${ }^{118}$. Os sobreviventes de doenças graves apresentavam níveis elevados de transporte de $\mathrm{O}_{2}{ }^{104}$. Vários investigadores avaliaram o papel da elevação do índice cardíaco e $\mathrm{DO}_{2}$ em pacientes criticamente enfermos. Estudos iniciais sugeriam efeito benéfico dessa estratégia ${ }^{104,119,120}$. No entanto, estudos maiores e metanálise dos estudos realizados não demonstraram diminuição de morbidade nem mortalidade desses pacientes ${ }^{114,117,121}$. Estudo prospectivo, controlado e aleatório que utilizou dobutamina sugere que a busca, a qualquer custo, de valores supranormais, sem respeitar a reserva fisiológica dos pacientes, aumenta a mortalidade ${ }^{121}$. 
QUESTÃO: A MONITORIZAÇÃO HEMODINÂMICA É BENÉFICA NA FASE INICIAL DO CHOQUE SÉPTICO?

Recomendação: Sim, a monitorização precoce é fundamental para diagnosticar hipoperfusão e guiar medidas terapêuticas nesses pacientes na tentativa de prevenir disfunções orgânicas.

Grau B1

Racional: Em pacientes com choque séptico, investigações realizadas em amostras heterogêneas que avaliaram a monitorização hemodinâmica e o uso de protocolos de suporte hemodinâmico, iniciados depois da instalação de falências orgânicas, têm contribuído para dúvidas sobre a eficácia do método. A terapia de otimização hemodinâmica guiada por metas pré-estabelecidas, quando iniciada precocemente, reduz a mortalidade de pacientes com sepse grave/choque séptico. $\mathrm{O}$ uso de um protocolo guiado por PVC, PAM e $\mathrm{SvO}_{2}$ reduziu significativamente a mortalidade. Rivers e col. relataram, em estudo prospectivo, controlado e aleatório, significativa diminuição da mortalidade $(30,5 \%)$ com a otimização precoce nas primeiras seis horas, utilizando como meta terapêutica uma saturação venosa central $>70 \%$, comparado ao grupo não otimizado $(46.5 \%)^{37}$. Pacientes otimizados receberam maior volume de fluidos e mais suporte inotrópico (principalmente dobutamina).

\section{QUESTÃO: PACIENTES COM BAIXO RISCO DE MORTE SE BENEFICIAM DA MONITORIZAÇÃO COM CAP?}

Recomendação: Não. Pacientes com baixo risco de morte não se beneficiam da monitorização invasiva com CAP.

Grau A1

Racional: Deve-se avaliar a relação risco-benefício de toda intervenção diagnóstica. A monitorização invasiva com CAP, embora considerado um método seguro quando utilizado em pacientes graves, devido à baixa incidência de complicações, deve ser evitado em pacientes estáveis com baixo risco de mortalidade, nos quais a terapia empírica não implique em maiores riscos. Neste caso, os riscos do método podem superar os eventuais benefícios. Uma metanálise investigou os resultados de 21 estudos com o uso do CAP e metas terapêuticas normais e supranormais. Não foi demonstrado efeito na sobrevida, com a abordagem de otimização hemodinâmica para valores normais ou supranormais, nos grupos com pacientes cirúrgicos de baixo risco $53,113,117$.

\section{CONCLUSÃO}

Todos os participantes do Consenso concordaram plenamente com a afirmação de que "A monitorização hemodinâmica por si só não é capaz de reduzir a mortalidade de pacientes graves. Os possíveis benefícios serão conseqüência da correta interpretação dos dados obtidos e do uso de protocolos de tratamento que permitam obtenção de metas hemodinâmicas adequadas".

\section{PAINEL DE ESPECIALISTAS DO CONSENSO BRA- SILEIRO DE MONITORIZAÇÃO E SUPORTE HEMO- DINÂMICO}

Coordenador: Ederlon Rezende, Diretor do Serviço de Terapia Intensiva do Hospital do Servidor Público Estadual (São Paulo-SP);

Comitê Consultivo: Álvaro Réa-Neto, Professor do Departamento de Clínica Médica da UFPR, Chefe da UTI adulto do Hospital de Clínicas da UFPR, Diretor do CEPETI - Centro de Estudos e Pesquisa em Terapia Intensiva (Curitiba-PR); Ciro Leite Mendes, Coordenador da UTI adulto do Hospital de Emergência e Trauma Senador Humberto Lucena e Hospital Santa Paula, Médico da Rotina da UTI adulto do Hospital Universitário - UFPB (João Pessoa-PB); Fernando Suparregui Dias, Professor da Faculdade de Medicina da PUC de Porto Alegre, Chefe da UTI geral do Hospital São Lucas da PUC de Porto Alegre (Porto Alegre-RS); Guilherme Schettino, Doutor em Medicina pela Faculdade de Medicina da USP, Médico Assistente da UTI Respiratória do HC da FMUSP, Médico Coordenador da UTI do Hospital Sírio Libanês (São Paulo-SP); Suzana Margareth Ajeje Lobo, Doutora de Medicina pela Universidade de São Paulo, Professora de clínica médica da Faculdade de Medicina de São José do Rio Preto, Coordenadora do Serviço de Terapia Intensiva do Hospital de Base - FAMERP (São José do Rio Preto-SP); Cid Marcos David, Presidente do Fundo de Educação e Pesquisa da Associação de Medicina Intensiva Brasileira, Doutor em Ciências Médicas, Professor Adjunto da UFRJ (Rio de Janeiro-RJ).

Painel de Especialistas: Alberto Barros, Médico Coordenador da UTI do Hospital Português de Recife (Recife-PE); Eliézer Silva, Doutor em Medicina, Médico 
Supervisor CTI Hospital Israelita Albert Einstein (São Paulo-SP); Gilberto Friedman, Editor Chefe da Revista Brasileira de Terapia intensiva; Médico do Hospital de Clínicas de Porto Alegre FAMED-UFRGS (Porto Alegre-RS); José Luiz Gomes do Amaral, Doutor em Medicina, Chefe da Disciplina de Anestesiologia, Dor e Terapia Intensiva da UNIFESP (São Paulo-SP); Marcelo Park, Médico Assistente da Unidade de Terapia Intensiva - Disciplina de Emergências Clínicas - HCFMUSP (São Paulo-SP); Maristela Monachini, Doutora em Medicina, Médica Assistente da UTI do Hospital Sírio Libanês (São Paulo-SP); Mirella Cristine de Oliveira, Médica Coordenadora do Hospital do Trabalhador (Curitiba-PR); Murillo Santucci César Assunção, Médico Coordenador Serviço de Terapia Intensiva do Hospital do Servidor Público Estadual (São Paulo-SP); Nelson Akamine, Médico Supervisor CTI Hospital Israelita Albert Einstein (São Paulo-SP); Patrícia Veiga C Mello, Médica Coordenadora da Disciplina de Emer- gência da Universidade Estadual do Piauí, Coordenadora da UTI do Hospital de Terapia Intensiva (TerezinaPI); Renata Andréa Pietro Pereira, Enfermeira Chefe do Serviço de Terapia Intensiva do Hospital do Servidor Público Estadual (São Paulo-SP); Rubens Costa FiIho, Médico Coordenador CTI do PROCARDÍACO (Rio de Janeiro-RJ); Sebastião Araújo, Médico, Professor Doutor Assistente Departamento de Cirurgia da FCMUNICAMP (Campinas-SP); Sérgio Félix Pinto, Médico Chefe da UTI do Hospital Universitário da UFMS (Campo Grande-MS); Sérgio Ferreira, Médico Chefe da UTI do Hospital Universitário Getúlio Vargas da UFAM (Manaus-AM); Simone Mattoso Mitushima, Enfermeira da UTI do Hospital Sírio Libanês (São Paulo-SP); Sydney Agareno, Médico Vice-Coordenador da UTI Geral do Hospital Português de Salvador (Salvador-BA); e Yuzeth Nóbrega de Assis Brilhante, Médica Coordenadora da UTI do Hospital da UNIMED João Pessoa (João Pessoa-PB).

\section{APÊNDICE - ALGORITMOS}

\section{A- Suporte Hemodinâmico}

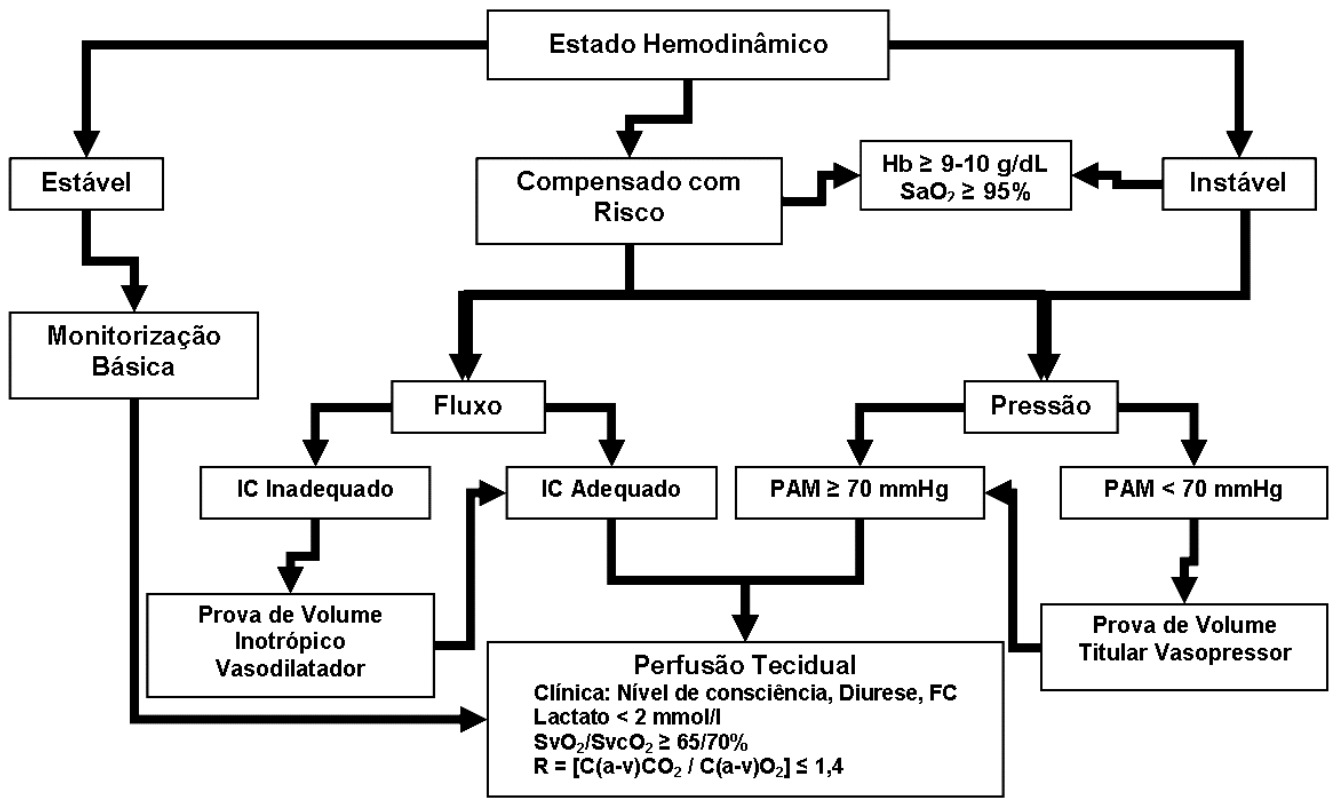

A - Suporte Hemodinâmico: Os pacientes estáveis podem ser monitorizados apenas com métodos básicos, mantendo-se vigilância quanto à manutenção de parâmetros adequados de perfusão tecidual. Entretanto, os pacientes instáveis, ou compensados com risco, além da garantia de uma oxigenação e níveis de hemoglobina adequados, deve-se utilizar métodos de monitorização que permitam a avaliação de pressão e fluxo. A observação dos níveis de fluxo e pressão permite a tomada de decisões para atingir a meta final de garantir adequada perfusão tecidual. 


\section{B- Prova de Volume}

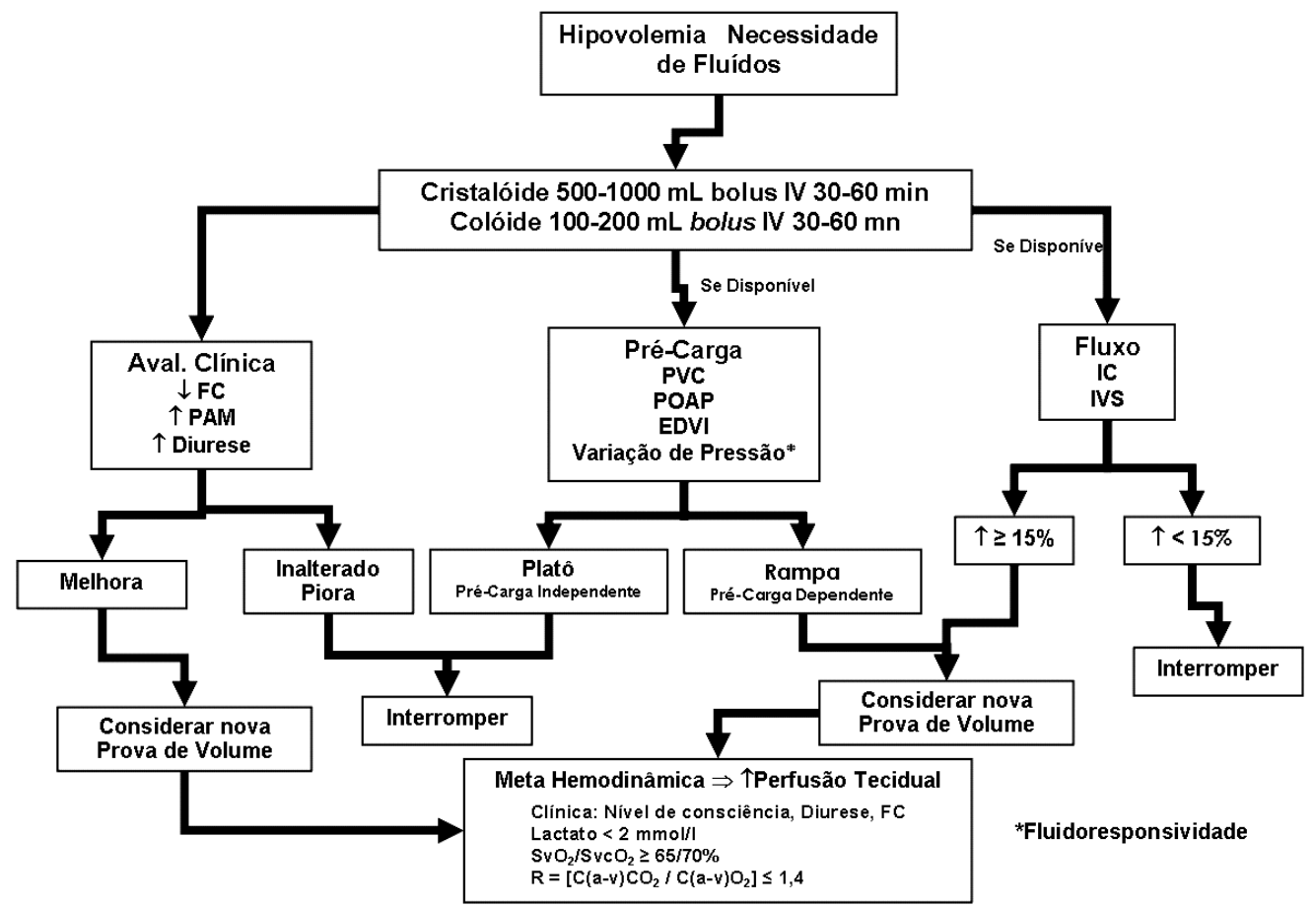

B - Prova de Volume: Pode ser realizada tanto com cristalóides (500 a $1000 \mathrm{~mL}$ ) quanto colóides (100 a $200 \mathrm{~mL}$ ) infundidos em 30 a 60 minutos. Caso se disponha apenas de monitorização básica, as provas serão repetidas de acordo com a melhora, ou intolerância à administração de fluídos. Se estiverem disponíveis métodos de avaliação da pré-carga ou fluidoresponsividade é possível identificar o comportamento fisiológico de acordo com o princípio de Frank-Starling. Pacientes na rampa da curva de fluxo/volume são pré-carga dependentes e costumam responder positivamente à prova de volume. A avaliação funcional através da prova de volume através da curva de Frank-Starling é mais completa se métodos de monitorização de fluxo estiverem disponíveis. São considerados respondedores os pacientes que aumentam o fluxo em mais de $15 \%$ após prova de volume.

\section{C- Uso de Inotrópicos}

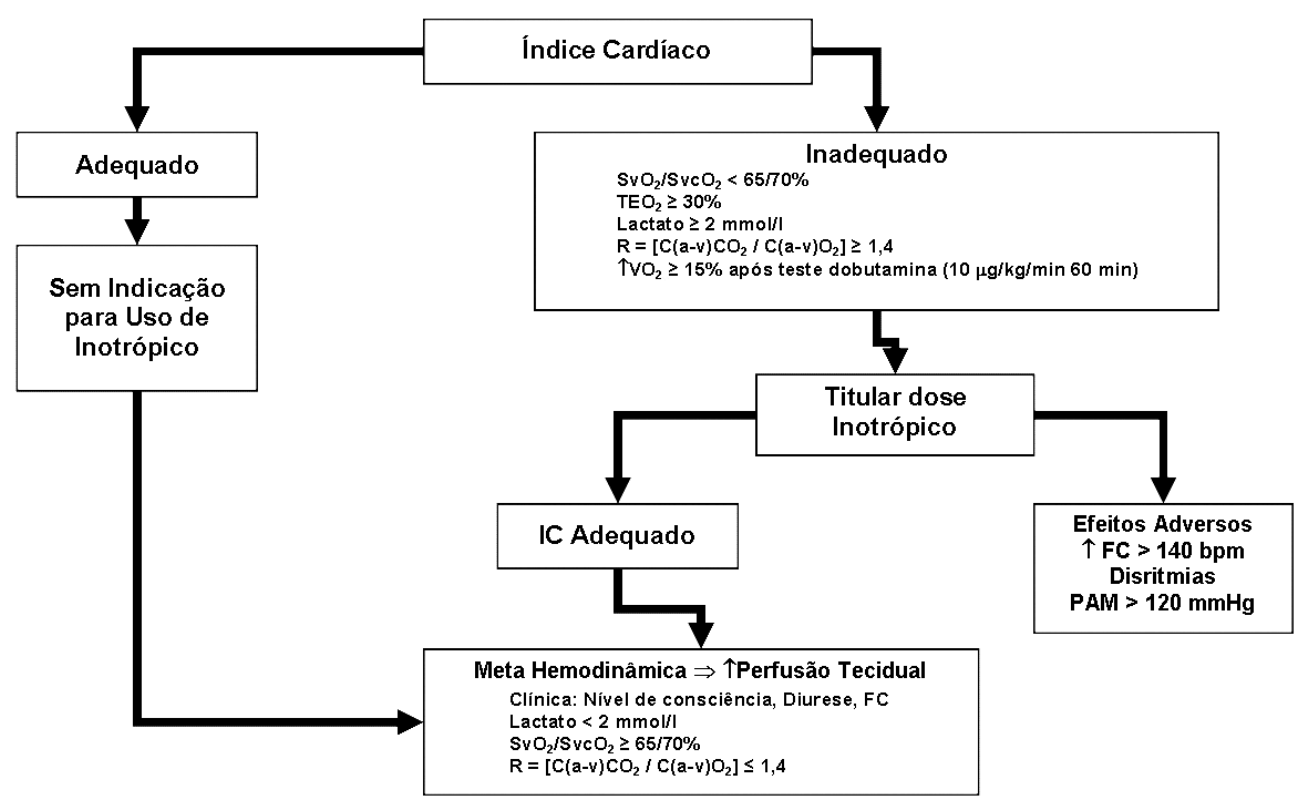

C - Uso de Inotrópicos: Débito cardíaco adequado é aquele que permite perfusão tecidual adequada independente de seu valor absoluto. Inotrópicos serão utilizados apenas quando o débito não for adequado para as necessidades do paciente, após reposição volêmica satisfatória. 
D- Uso de Vasodilatadores

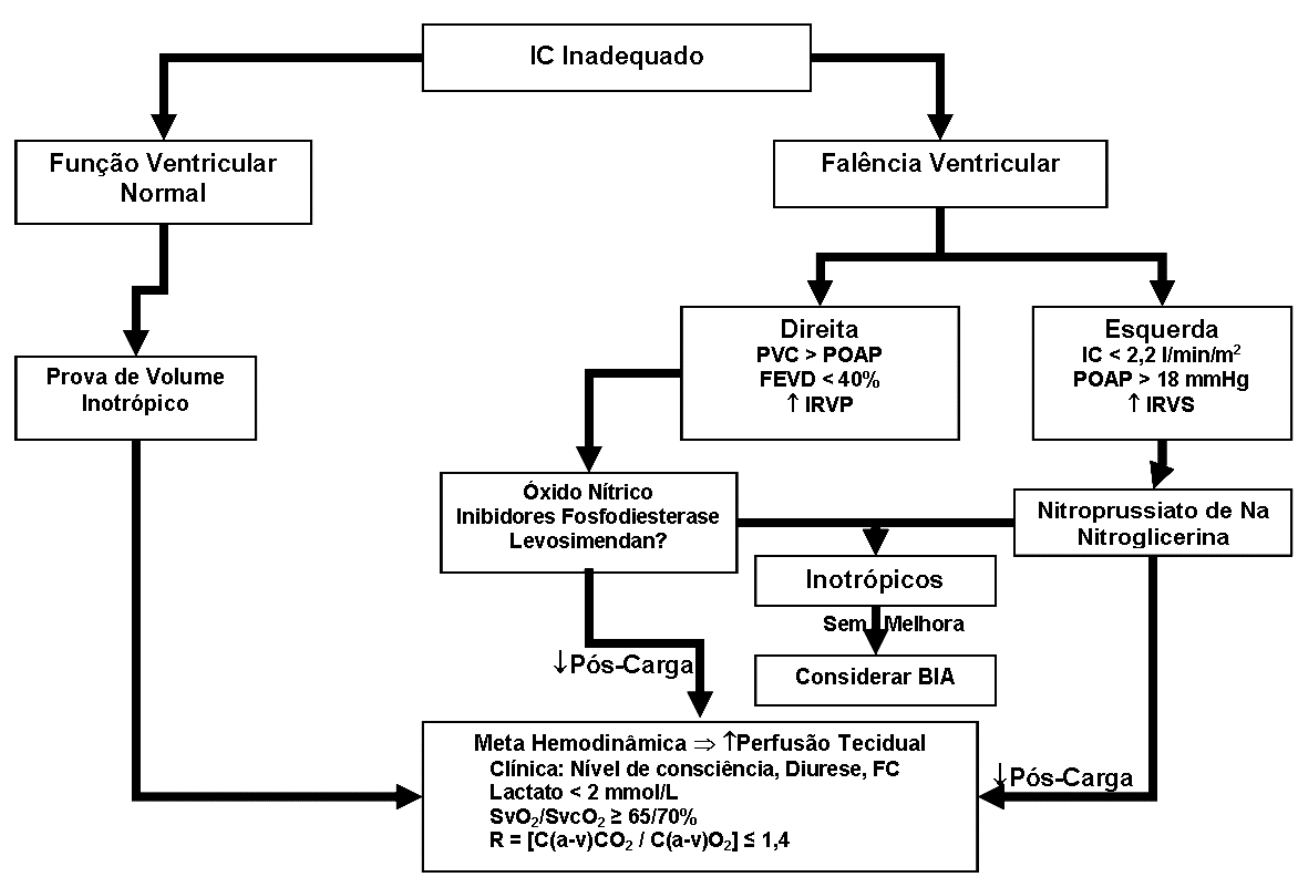

D - Uso de Vasodilatadores: Na presença de débito cardíaco inadequado com função ventricular preservada, a resposta à provas de volume ou inotrópoicos costuma ser boa. Entretanto, na presença de falência ventricular, a redução da pós-carga com o uso de vasodilatadores, está indicada. A escolha do vasodilatador deve considerar a ação preferencial do fármaco na circulação pulmonar (falência direita), ou sistêmica (falência esquerda).

\section{PAINEL DE ESPECIALISTAS DO CONSENSO BRA- SILEIRO DE MONITORIZAÇÃO E SUPORTE HEMO- DINÂMICO}

Comitê Consultivo: Suzana Margareth Ajeje Lobo, Doutora de Medicina pela Universidade de São Paulo, Professora de Clínica Médica da Faculdade de Medicina de São José do Rio Preto, Coordenadora do Serviço de Terapia Intensiva do Hospital de Base - FAMERP (São José do Rio Preto, SP); Ederlon Rezende, Diretor do Serviço de Terapia Intensiva do Hospital do Servidor Público Estadual (São Paulo, SP); Ciro Leite Mendes, Coordenador da UTI Adulto do Hospital de Emergência e Trauma Senador Humberto Lucena e Hospital Santa Paula, Médico da Rotina da UTI Adulto do Hospital Universitário - UFPB (João Pessoa, PB); Álvaro RéaNeto, Professor do Departamento de Clínica Médica da UFPR, Chefe da UTI adulto do Hospital de Clínicas da UFPR, Diretor do CEPETI - Centro de Estudos e Pesquisa em Terapia Intensiva (Curitiba, PR); Cid Marcos David, Presidente do Fundo de Educação e Pesquisa da Associação de Medicina Intensiva Brasileira, Doutor em Ciências Médicas, Professor Adjunto da UFRJ (Rio de Janeiro-RJ). Fernando Suparregui Dias, Professor da Faculdade de Medicina da PUC de Porto Alegre, Chefe da UTI Geral do Hospital São Lucas da PUC de Porto Alegre (Porto Alegre, RS); Guilherme Schettino, Doutor em Medicina pela Faculdade de Medicina da USP, Médico Assistente da UTI Respiratória do HC da FMUSP, Médico Coordenador da UTI do Hospital Sírio Libanês (São Paulo, SP)

Painel de Especialistas: Alberto Barros, Médico Coordenador da UTI do Hospital Português de Recife (Recife, PE); Eliézer Silva, Doutor em Medicina, Médico Supervisor CTI Hospital Israelita Albert Einstein (São Paulo, SP); Gilberto Friedman, Editor Chefe da Revista Brasileira de Terapia Intensiva; Médico do Hospital de Clínicas de Porto Alegre FAMED-UFRGS (Porto Alegre, RS); José Luiz Gomes do Amaral, Doutor em Medicina, Chefe da Disciplina de Anestesiologia, Dor e Terapia Intensiva da UNIFESP (São Paulo, SP); Marcelo Park, Médico Assistente da Unidade de Terapia Intensiva Disciplina de Emergências Clínicas - HC-FMUSP (São Paulo, SP); Maristela Monachini, Doutora em Medicina, Médica Assistente da UTI do Hospital Sírio Libanês (São Paulo-SP); Mirella Cristine de Oliveira, Médica Coordenadora do Hospital do Trabalhador (Curitiba, PR); Murillo Santucci César Assunção, Médico Assistente 
da Disciplina de Anestesiologia, Dor e Terapia Intensiva da UNIFESP (São Paulo, SP); Nelson Akamine, Médico Supervisor CTI Hospital Israelita Albert Einstein (São Paulo, SP); Patrícia Veiga C Mello, Médica Coordenadora da Disciplina de Emergência da Universidade Estadual do Piauí, Coordenadora da UTI do Hospital de Terapia Intensiva (Terezina, PI); Renata Andréa Pietro Pereira, Enfermeira Chefe do Serviço de Terapia Intensiva do Hospital do Servidor Público Estadual (São Paulo, SP); Rubens Costa Filho, Médico Coordenador CTI do PROCARDÍACO (Rio de Janeiro, RJ); Sebastião Araújo, Médico, Professor Doutor Assistente Departamento de Cirurgia da FCM-UNICAMP (Campinas, SP); Sérgio Félix Pinto, Médico Chefe da UTI do Hospital Universitário da UFMS (Campo Grande, MS); Sérgio Ferreira, Médico Chefe da UTI do Hospital Universitário Getúlio Vargas da UFAM (Manaus, AM); Simone Mattoso Mitushima, Enfermeira da UTI do Hospital Sírio Libanês (São Paulo, SP); Sydney Agareno, Médico Vice-Coordenador da UTI Geral do Hospital Português de Salvador (Salvador, BA); Yuzeth Nóbrega de Assis Brilhante, Médica Coordenadora da UTI do Hospital da UNIMED João Pessoa (João Pessoa, PB).

\section{REFERÊNCIAS}

01. Rackow EC, Falk JL, Fein IA et al - Fluid resuscitation in circulatory shock: a comparison of the cardiorespiratory effects of albumin, hetastarch, and saline solutions in patients with hypovolemic and septic shock. Crit Care Med, 1983;11:839-850.

02. Choi PT, Yip G, Quinonez LG et al - Crystalloids vs. colloids in fluid resuscitation: a systematic review. Crit Care Med, 1999;27:200-210.

03. Roberts I, Alderson P, Bunn F et al - Colloids versus crystalloids for fluid resuscitation in critically ill patients. Cochrane Database Syst Rev, 2004;18:CD000567.

04. Schierhout G, Roberts I - Fluid resuscitation with colloid or crystalloid solutions in critically ill patients: a systematic review of randomised trials. BMJ, 1998;316:961-964.

05. Stephens R, Mythen M - Optimizing intraoperative fluid therapy. Curr Opin Anaesth, 2003;16:385-392.

06. Scheingraber S, Rehm M, Sehmisch $\mathrm{C}$ et al - Rapid saline infusion produces hyperchloremic acidosis in patients undergoing gynecologic surgery. Anesthesiology, 1999:90:1265-1270.

07. Oliveira RP, Velasco I, Soriano F et al - Clinical review: Hypertonic saline resuscitation in sepsis. Crit Care, 2002;6:418-423.

08. Kramer GC - Hypertonic resuscitation: physiologic mechanisms and recommendations for trauma care. J Trauma, 2003;54:(Suppl5):S89-S99.

09. Brown MD - Evidence-based emergency medicine. Hypertonic versus isotonic crystalloid for fluid resuscitation in critically ill patients. Ann Emerg Med, 2002:40:113-114.

10. Mattox KL, Maningas PA, Moore EE et al - Prehospital hypertonic saline/ dextran infusion for post-traumatic hypotension. The U.S.A. Multicenter Trial. Ann Surg, 1991;213:482-491.

11. Vassar MJ, Fischer RP, O'Brien PE et al - A multicenter trial for resuscitation of injured patients with $7.5 \%$ sodium chloride. The effect of added dextran 70. The Multicenter Group for the Study of Hypertonic Saline in Trauma Patients. Arch Surg, 1993;128:1003-1013.

12. Berger S, Schurer L, Hartl R et al - Reduction of post-traumatic intracranial hypertension by hypertonic/hyperoncotic saline/dextyran and manitol. Neurosurgery, 1985:37:98-107.
13. Bentsen G, Breivik H, Lundar T et al - Predictable reduction of intracranial hypertension with hypertonic saline hydroxyethyl starch: a prospective clinical trial in critically ill patients with subarachnoid haemorrhage. Acta Anaesthesiol Scand, 2004;48:1089-1095.

14. Wade CE, Kramer GC, Grady JJ et al - Efficacy of hypertonic $7.5 \%$ saline and $6 \%$ dextran-70 in treating trauma: a meta-analysis of controlled clinical studies. Surgery, 1997;122:609-616.

15. Friedman G, Berlot G, Kahn RJ et al - Combined measurements of blood lactate concentrations and gastric intramucosal $\mathrm{pH}$ in patients with severe sepsis. Crit Care Med, 1995;23:1184-1193.

16. Marx G - Fluid therapy in sepsis with capillary leakage. Eur J Anaesthesiol, 2003;20:429-442.

17. Boldt $\mathrm{J}$ - Fluid choice for resuscitation of the trauma patient: a review of the physiological, pharmacological, and clinical evidence. Can J Anaesth, 2004;51:500-513.

18. Entholzner EK, Mielke LL, Calatzis AN et al - Coagulation effects of a recently developed hydroxyethyl starch (HES 130/0.4) compared to hydroxyethyl starches with higher molecular weight. Acta Anaesthesiol Scand, 2000;44:1116-1121.

19. Franz A, Braunlich P, Gamsjager $T$ et al - The effects of hydroxyethyl starches of varying molecular weights on platelet function. Anesth Analg, 2001;92:1402-1407.

20. Bunn F, Roberts I, Tasker R et al - Hypertonic versus isotonic crystalloid for fluid resuscitation in critically ill patients. Cochrane Database Syst Rev, 2002;1:CD002045.

21. Schortgen F, Lacherade JC, Bruneel F et al - Effects of hydroxyethylstarch and gelatin on renal function in severe sepsis: a multicentre randomised study. Lancet, 2001;357:(9260):911-916.

22. Barron ME, Wilkes MM, Navickis RJ - A systematic review of the comparative safety of colloids. Arch Surg, 2004;139:552-563.

23. Legendre C, Thervet E, Page B et al - Hydroxyethylstarch and osmotic-nephrosis-like lesions in kidney transplantation. Lancet, 1993;342:(8865):248-249.

24. Parker MJ, Griffiths R, Boyle A - Preoperative saline versus gelatin for hip fracture patients; a randomized trial of 396 patients. $\mathrm{Br} \mathrm{J}$ Anaesth, 2004;92:67-70.

25. Miller CL, Lim RC - Dextran as a modulator of immune and coagulation activities in trauma patients. J Surg Res, 1985;39:183-191.

26. Wilkes MM, Navickis RJ - Patient survival after human albumin administration. A meta-analysis of randomized, controlled trials. Ann Intern Med, 2001;135:149-164.

27. Finfer $\mathrm{S}$, Bellomo $\mathrm{R}$, Boyce $\mathrm{N}$ et al - A comparison of albumin and saline for fluid resuscitation in the intensive care unit. $\mathrm{N}$ Engl $\mathrm{J} \mathrm{Med,}$ 2004;350:2247-2256.

28. Gentilini P, Casini-Raggi V, Di Fiore G et al - Albumin improves the response to diuretics in patients with cirrhosis and ascites: results of a randomized, controlled trial. J Hepatol, 1999;30:639-645.

29. Gines P, Arroyo V, Quintero E et al - Comparison of paracentesis and diuretics in the treatment of cirrhotics with tense ascites. Results of a randomized study. Gastroenterology, 1987;93:234-241.

30. Salerno F, Badalamenti S, Incerti $P$ et al - Repeated paracentesis and i.v. albumin infusion to treat 'tense' ascites in cirrhotic patients. A safe alternative therapy. J Hepat, 1987;5:102-108.

31. Quinlan GJ, Mumby S, Martin GS et al - Albumin influences total plasma antioxidant capacity favorably in patients with acute lung injury. Crit Care Med, 2004;32:755-759.

32. Martin GS, Mangialardi RJ, Wheeler AP et al - Albumin and furosemide therapy in hypoproteinemic patients with acute lung injury. Crit Care Med, 2002;30:2175-2182.

33. Martin GS - Fluid balance and colloid osmotic pressure in acute respiratory failure: emerging clinical evidence. Crit Care, 2000;4:(Suppl2): S21-S25.

34. Sedrakyan A, Gondek K, Paltiel D et al - Volume expansion with albumin decreases mortality after coronary artery bypass graft surgery. Chest, 2003;123:1853-1857.

35. Fernandes CJ Jr, Akamine N, de Marco FV et al - Red blood cell transfusion does not increase oxygen consumption in critically ill septic patients. Crit Care, 2001:5:362-367.

36. Walsh TS, McArdle F, McLellan SA et al - Does the storage time of transfused red blood cells influence regional or global indexes of tissue oxygenation in anemic critically ill patients? Crit Care Med, 2004;32:364371. 
37. 37. 37. Rivers E, Nguyen B, Havstad S et al - Early goal-directed therapy in the treatment of severe sepsis and septic shock. N Engl J Med, 2001;345:1368-1377.

38. Nguyen BV, Bota DP, Melot C et al - Time course of hemoglobin concentrations in nonbleeding intensive care unit patients. Crit Care Med, 2003;31:406-410

39. Weil MH - Blood transfusions. Crit Care Med, 2003;31:2397-2398.

40. Borum ML, Lynn J, Zhong Z - Blood transfusion administration in seriously ill patients: an evaluation of SUPPORT data. Study to Understand Prognoses and Preferences for Outcomes and Risks of Treatments. $J$ Am Geriatr Soc, 2000;48:(Suppl5):S39-S43.

41. Hebert PC, Wells G, Tweeddale M et al - Does transfusion practice affect mortality in critically ill patients? Transfusion Requirements in Critical Care (TRICC) Investigators and the Canadian Critical Care Trials Group. Am J Respir Crit Care Med, 1997;155:1618-1623.

42. Whitten CS, Chia Z, Gresecke AH et al - An analysis of survival in patients with traumatic injuries who received transfusions of forty units or more. Anesthesiology, 1995;(83):A218

43. Taylor RW, Manganaro L, O'Brien $\mathrm{J}$ et al - Impact of allogenic packed red blood cell transfusion on nosocomial infection rates in the critically ill patient. Crit Care Med, 2002;30:2249-2254.

44. Shorr AF, Duh M-S, Kelly KM et al - Red blood cell transfusion and ventilator-associated pneumonia: a potential link? Crit Care Med, 2004;32:666-674

45. Vincent JL, Baron JF, Reinhart $\mathrm{K}$ et al - Anemia and blood transfusion in critically ill patients. JAMA, 2002;288:1499-1507.

46. Corwin HL, Surgenor SD, Gettinger A - Transfusion practice in the critically ill. Crit Care Med, 2003;31:(Suppl12):S668-S671.

47. Baguneid MS, Welch $\mathrm{M}$, Bukhari $\mathrm{M}$ et al - A randomized study to evaluate the effect of a perioperative infusion of dopexamine on colonic mucosal ischemia after aortic surgery. J Vasc Surg, 2001;33:758-763.

48. Hannemann L, Reinhart K, Meier-Hellmann A et al - Dopexamine hydrochloride in septic shock. Chest, 1996;109:756-760.

49. Lund $\mathrm{N}$, de Asla RJ, Cladis $\mathrm{F}$ et al - Dopexamine hydrochloride in septic shock: effects on oxygen delivery and oxygenation of gut, liver, and muscle. J Trauma, 1995:38:767-775.

50. Colardyn FC, Vandenbogaerde JF, Vogelaers DP et al - Use of dopexamine hydrochloride in patients with septic shock. Crit Care Med, 1989;17:999-1003.

51. Ralph CJ, Tanser SJ, Macnaughton PD et al - A randomised controlled trial investigating the effects of dopexamine on gastrointestina function and organ dysfunction in the critically ill. Intensive Care Med, 2002;28:884-890.

52. Thoren A, Elam M, Ricksten SE - Differential effects of dopamine, dopexamine, and dobutamine on jejunal mucosal perfusion early after cardiac surgery. Crit Care Med, 2000;28:2338-2343.

53. Takala J, Meier-Hellmann A, Eddleston $\mathrm{J}$ et al - Effect of dopexamine on outcome after major abdominal surgery: a prospective, randomized, controlled multicenter study. European Multicenter Study Group on Dopexamine in Major Abdominal Surgery. Crit Care Med, 2000;28:34173423.

54. Rosner MJ, Rosner SD, Johnson AH - Cerebral perfusion pressure: management protocol and clinical results. J Neurosurg, 1995;83:949-962.

55. Oertel M, Kelly DF, Lee JH et al - Efficacy of hyperventilation, blood pressure elevation, and metabolic suppression therapy in controlling intracranial pressure after head injury. J Neurosurg, 2002:97:1045-1053.

56. Takala $\mathrm{J}$ - Non-conventional vasopressors in septic shock: effects on hepatosplanchnic blood flow. Schweiz Med Wochenschr, 2000;130:1937-1941.

57. Gregory JS, Bonfiglio MF, Dasta JF et al - Experience with phenylephrine as a component of the pharmacologic support of septic shock. Crit Care Med, 1991;19:1395-1400.

58. Bellissant E, Annane D - Effect of hydrocortisone on phenylephrine-mean arterial pressure dose-response relationship in septic shock. Clin Pharmacol Ther, 2000;68:293-303.

59. Cooper DW, Mowbray P - Ephedrine or phenylephrine to prevent or treat hypotension during spinal anaesthesia for caesarean section. Int J Obstet Anesth, 2004;13:197-198.

60. Wenzel V, Krismer AC, Arntz HR et al - A comparison of vasopressin and epinephrine for out-of-hospital cardiopulmonary resuscitation. $\mathrm{N}$ Engl J Med, 2004;350:105-113

61. Stiell IG, Hebert PC, Wells GA et al - Vasopressin versus epinephrine for inhospital cardiac arrest: a randomised controlled trial. Lancet,
2001;358:(9276):105-109

62. Holmes CL, Patel BM, Russell JA et al - Physiology of vasopressin relevant to management of septic shock. Chest, 2001;120:989-1002.

63. Kinoshita $\mathrm{Y}$, Yahata $\mathrm{K}$, Yoshioka $\mathrm{T}$ et al - Long-term renal preservation after brain death maintained with vasopressin and epinephrine. Transpl Int, 1990;3:15-18

64. van Haren FM, Rozendaal FW, van der Hoeven JG - The effect of vasopressin on gastric perfusion in catecholamine-dependent patients in septic shock. Chest, 2003;124:2256-2260.

65. Dunser MW, Mayr AJ, Ulmer $\mathrm{H}$ et al - Arginine vasopressin in advanced vasodilatory shock: a prospective, randomized, controlled study. Circulation, 2003;107:2313-2319.

66. Lipman J, Roux A, Kraus P - Vasoconstrictor effects of adrenaline in human septic shock. Anaesth Intensive Care, 1991:19:61-65.

67. Wilson W, Lipman J, Scribante $\mathrm{J}$ et al - Septic shock: does adrenaline have a role as a first-line inotropic agent? Anaesth Intensive Care, 1992;20:470-474

68. Levy B, Bollaert PE, Charpentier $\mathrm{C}$ et al - Comparison of norepinephrine and dobutamine to epinephrine for hemodynamics, lactate metabolism, and gastric tonometric variables in septic shock: a prospective, randomized study. Intensive Care Med, 1997;23:282-287.

69. De Backer D, Creteur J, Silva E et al - Effects of dopamine, norepinephrine, and epinephrine on the splanchnic circulation in septic shock: which is best? Crit Care Med, 2003;31:1659-1667.

70. Jardin F, Sportiche M, Bazin M et al - Dobutamine: a hemodynamic evaluation in human septic shock. Crit Care Med, 1981;9:329-332.

71. Ronco JJ, Fenwick JC, Wiggs BR et al - Oxygen consumption is independent of increases in oxygen delivery by dobutamine in septic patients who have normal or increased plasma lactate. Am Rev Respir Dis, 1993;147:25-31.

72. Gutierrez G, Clark C, Brown SD et al - Effect of dobutamine on oxygen consumption and gastric mucosal pH in septic patients. Am J Respir Crit Care Med, 1994;150:324-329.

73. Sun Q, Tu Z, Lobo S et al - Optimal adrenergic support in septic shock due to peritonitis. Anesthesiology, 2003;98:888-896.

74. Hoogenberg K, Smit AJ, Girbes AR - Effects of low-dose dopamine on renal and systemic hemodynamics during incremental norepinephrine infusion in healthy volunteers. Crit Care Med, 1998;26:260-265.

75. Lherm T, Troche G, Rossignol M et al - Renal effects of low-dose dopamine in patients with sepsis syndrome or septic shock treated with catecholamines. Intensive Care Med, 1996;22:213-219.

76. Schreuder WO, Schneider AJ, Groeneveld AB et al - Effect of dopamine vs orepinephrine on hemodynamics in septic shock. Emphasis on right ventricular performance. Chest, 1989;95:1282-1288.

77. Ruokonen E, Takala J, Kari A et al - Regional blood flow and oxygen transport in septic shock. Crit Care Med, 1993;21:1296-1303.

78. Marik PE, Mohedin M - The contrasting effects of dopamine and norepinephrine on systemic and splanchnic oxygen utilization in hyperdynamic sepsis. JAMA, 1994:272:1354-1357.

79. Martin C, Papazian L, Perrin G et al - Norepinephrine or dopamine for the treatment of hyperdynamic septic shock? Chest, 1993;103:1826-1831.

80. Bellomo R, Chapman M, Finfer S et al - Low-dose dopamine in patients with early renal dysfunction: a placebo-controlled randomised trial. Australian and New Zealand Intensive Care Society (ANZICS) Clinical Trials Group. Lancet, 2000;356(9248):2139-2143.

81. Kellum JA, M Decker J - Use of dopamine in acute renal failure: a metaanalysis. Crit Care Med, 2001;29:1526-1531.

82. Desjars $\mathrm{P}$, Pinaud $\mathrm{M}$, Bugnon $\mathrm{D}$ et al - Norepinephrine therapy has no deleterious renal effects in human septic shock. Crit Care Med, 1989:17:426-429.

83. Martin C, Viviand X, Leone $\mathrm{M}$ et al - Effect of norepinephrine on the outcome of septic shock. Crit Care Med, 2000;28:2758-2765.

84. Meadows D, Edwards JD, Wilkins RG et al - Reversal of intractable septic shock with norepinephrine therapy. Crit Care Med, 1988;16:663-666.

85. Dasta JF - Norepinephrine in septic shock: renewed interest in an old drug. DICP, 1990;24:153-156.

86. Redl-Wenzl EM, Armbruster C, Edelmann G et al - The effects of norepinephrine on hemodynamics and renal function in severe septic shock states. Intensive Care Med, 1993;19:151-154.

87. Task Force of the American College of Critical Care Medicine SCCM. Practice parameters for hemodynamic support of sepsis in adult patients in sepsis. Crit Care Med, 1999;27:639-660. 
88. Anderson JL - Hemodynamic and clinical benefits with intravenous milrinone in severe chronic heart failure: results of a multicenter study in the United States. Am Heart J, 1991;121:1956-1964.

89. Felker GM, Benza RL, Chandler AB et al - Heart failure etiology and response to milrinone in decompensated heart failure: results from the OPTIME-CHF study. J Am Coll Cardiol, 2003;41:997-1003.

90. Aranda JM Jr, Schofield RS, Pauly DF et al - Comparison of dobutamine versus milrinone therapy in hospitalized patients awaiting cardiac transplantation: a prospective, randomized trial. Am Heart J, 2003;145:324329.

91. Cuffe MS, Califf RM, Adams KF Jr et al - Short-term intravenous milrinone for acute exacerbation of chronic heart failure: a randomized controlled trial. JAMA, 2002;287:1541-1547.

92. Heinz G, Geppert A, Delle Karth G et al - IV milrinone for cardiac output increase and maintenance: comparison in nonhyperdynamic SIRS/sepsis and congestive heart failure. Intensive Care Med, 1999;25:620-624.

93. Boldt J, Brosch C, Suttner S et al - Prophylactic use of the phospodiesterase III inhibitor enoximone in elderly cardiac surgery patients: effect on hemodynamics, inflammation, and markers of organ function. Intensive Care Med, 2002;28:1462-1469.

94. Kivikko M, Antila S, Eha $\mathrm{J}$ et al - Pharmacodynamics and safety of a new calcium sensitizer, levosimendan, and its metabolites during an extended infusion in patients with severe heart failure. J Clin Pharmacol, 2002;42:43-51.

95. Follath F, Cleland JG, Just $\mathrm{H}$ et al - Efficacy and safety of intravenous levosimendan compared with dobutamine in severe low-output heart failure (the LIDO study): a randomised double-blind trial. Lancet, 2002;360:(9328):196-202.

96. Jenkins RC, Ross RJM - The endocrinology of the critically ill: current opinion. Curr Opin Endocrinol Diab, 1996:3:138-145.

97. Sprung CL, Caralis PV, Marcial EH et al - The effects of high-dose corticosteroids in patients with septic shock. A prospective, controlled study. N Engl J Med, 1984;311:1137-1143.

98. The Veterans Administration Systemic Sepsis Cooperative Study Group. Effect of high-dose glucocorticoid therapy on mortality in patients with clinical signs of systemic sepsis. N Engl J Med, 1987;317:659-665.

99. Bone RC, Fisher CJ Jr, Clemmer TP et al - A controlled clinical trial of high-dose methylprednisolone in the treatment of severe sepsis and septic shock. N Engl J Med, 1987;317:653-658.

100. Annane D, Sebille V, Charpentier C et al - Effect of treatment with low doses of hydrocortisone and fludrocortisone on mortality in patients with septic shock. JAMA, 2002;288:862-871.

101. Briegel J, Forst H, Haller M et al - Stress doses of hydrocortisone reverse hyperdynamic septic shock: a prospective, randomized, double-blind, single-center study. Crit Care Med, 1999; 27:723-732.

102. Bollaert PE, Charpentier C, Levy B et al - Reversal of late septic shock with supraphysiologic doses of hydrocortisone. Crit Care Med, 1998;26:645-650.

103. Dellinger RP, Carlet JM, Masur $\mathrm{H}$ et al - Surviving sepsis campaign guidelines for management of severe sepsis and septic shock. Crit Care Med, 2004;32:858-873.
104. Shoemaker WC, Appel PL, Kram HB et al - Prospective trial of supranormal values of survivors as therapeutic goals in high-risk surgical patients. Chest, 1988;94:1176-1186.

105. Schultz RJ, Whitfield GF, LaMura JJ et al - The role of physiologic monitoring in patients with fractures of the hip. J Trauma, 1985;25:309-316.

106. Boyd O, Grounds RM, Bennett ED - A randomized clinical trial of the effect of deliberate perioperative increase of oxygen delivery on mortality in high-risk surgical patients. JAMA, 1993;270:2699-2707.

107. Yu M, Takanishi D, Myers SA et al - Frequency of mortality and myocardial infarction during maximizing oxygen delivery: a prospective, randomized trial. Crit Care Med, 1995;23:1025-1032.

108. Lobo SM, Salgado PF, Castillo VG et al - Effects of maximizing oxygen delivery on morbidity and mortality in high-risk surgical patients. Crit Care Med, 2000;28:3396-3404.

109. Wilson J, Woods I, Fawcett $\mathrm{J}$ et al - Reducing the risk of major elective surgery: randomised controlled trial of preoperative optimisation of oxygen delivery. BMJ, 1999;318:(7191):1099-1103.

110. Berlauk JF, Abrams JH, Gilmour IJ et al - Preoperative optimization of cardiovascular hemodynamics improves outcome in peripheral vascular surgery. A prospective, randomized clinical trial. Ann Surg, 1991;214:289299.

111. Ziegler DW, Wright JG, Choban PS et al - A prospective randomized trial of preoperative "optimization" of cardiac function in patients undergoing elective peripheral vascular surgery. Surgery, 1997;122:584-592.

112. Valentine RJ, Duke ML, Inman MH et al - Effectiveness of pulmonary artery catheters in aortic surgery: a randomized trial. J Vasc Surg, 1998;27:203-211

113. Sandham JD, Hull RD, Brant RF et al - A randomized, controlled trial of the use of pulmonary-artery catheters in high-risk surgical patients. $\mathrm{N}$ Engl J Med, 2003;348:5-14.

114. Gattinoni L, Brazzi L, Pelosi P et al - A trial of goal-oriented hemodynamic therapy in critically ill patients. SvO2 Collaborative Group. N Engl J Med, 1995;333:1025-1032.

115. Ivanov R, Allen J, Calvin JE - The incidence of major morbidity in critically ill patients managed with pulmonary artery catheters: a meta-analysis. Crit Care Med, 2000;28:615-619.

116. Heyland DK, Cook DJ, King D et al - Maximizing oxygen delivery in critically ill patients: a methodologic appraisal of the evidence. Crit Care Med, 1996;24:517-524.

117. Kern JW, Shoemaker WC - Meta-analysis of hemodynamic optimization in high-risk patients. Crit Care Med, 2002;30:1686-1692.

118. Pittet JF, Pastor CM, Morel DR - Spontaneous high systemic oxygen delivery increases survival rate in awake sheep during sustained endotoxemia. Crit Care Med, 2000;28:496-503.

119. Tuchschmidt J, Fried J, Astiz M et al - Elevation of cardiac output and oxygen delivery improves outcome in septic shock. Chest, 1992;102:216-220.

120. Yu M, Levy MM, Smith $P$ et al - Effect of maximizing oxygen delivery on morbidity and mortality rates in critically ill patients: a prospective, randomized, controlled study. Crit Care Med, 1993;21:830-838.

121. Hayes MA, Timmins AC, Yau EH et al - Elevation of systemic oxygen delivery in the treatment of critically ill patients. $\mathrm{N}$ Engl $\mathrm{J}$ Med, 1994;330:1717-1722. 